\title{
Risk Factors and Management of Unexplained Limb Pain among Growing Children in a Tertiary Hospital
}

\author{
Yousuf $\mathrm{HA}^{1}$, Quadir MEU ${ }^{2}$ \\ DOI:https://doi.org/10.3329/jafmc.v16i2.55301
}

\begin{abstract}
Introduction: Recurrent lower limb pain (growing pain) is the most common presenting problem of children referred to pediatric rheumatology clinics. The exact nature and aetiology still remains unclear despite the various hypotheses and theories presented in the international literature. Parents become apprehensive as physician are unsure regarding accurate diagnosis of unexplained limb pain.
\end{abstract}

Objectives: To determine the risk factors of unexplained limb pain in growing children and measures taken for their management.

Materials and Methods: This cross sectional study was conducted among 60 children of 3 to 12 years who presented with unexplained limb pains between July to December, 2012 in Paediatric OPD of Combined Military Hospital (CMH) Dhaka.

Results: Mean age of the respondents was 7.4 years. Prevalence of growing pain was $75 \%$, overweight $13.3 \%$ and obesity was $15.6 \%$. The calf (37.3\%) was the most common affected site for pain and in $68.3 \%$ and $31.7 \%$ cases pain occurred during night and evening respectively. Pain frequency was as follows: daily $8 \%$; weekly 48\%; monthly 31\%; and every 3 months $13 \%$. Growing Pain usually occur at slow growing period (80.4\%) than rapid growing period (19.6\%). The main therapeutic approach was massaging (84.4\%) the painful limbs and to a lesser extent, the intake of oral anti-inflammatory agents (31.1\%). All patients had laboratory tests within normal values.

Conclusions: Growing pain (GP) is a frequent non-inflammatory syndrome that is relatively common in children and usually benign. It commonly affects the lower extremities of children. Precise history taking and physical examination makes clinical diagnosis easier. Patients' and family reassurance is of utmost importance in management of GP.

Key-words: Growing Pain, Unexplained limb pain, Children

\section{Introduction}

Recurrent lower limb pain (growing pain) constitutes the most frequent cause of musculoskeletal pain in children ${ }^{1}$. It was first mentioned by French doctor Duchamp ${ }^{2}$ in early 1823 , since than little advancement has been made in understanding the patho- physiological mechanism. The most useful set of diagnostic criteria were created by Petersen ${ }^{3,4}$ and completed by Russel and Abu-Arafeh ${ }^{5}$ despite the earlier efforts of many researchers. Medical science is still unable to fully explain the exact causes of the discomfort experienced by up to one third of all children at some time during early childhood ${ }^{6}$. The proposed causes of Growing pain (GP) according to Yosef Uziel and Philip J Hashkes are: low pain threshold, over use, low bone strength density, mechanical strains due to flat foot, blood perfusion change, family environment, stress and psychological disposition ${ }^{6,7}$.

Majority of the limb pain are due to Growing pain (GP) which can be diagnosed by using Standard Criteria'. Growing pain exemplifies a type of non-inflammatory syndrome. It is also known as Benign Nocturnal Limb Pain (BNLP) especially when they occur in the evening or at night time. These pains are much more common than all other inflammatory pain observed in children. The prevalence of GP ranges from $10-35 \%$ of children. Oster found that as many as $15 \%$ of school-age children have occasional limb pain ${ }^{9}$ and recently Evans and Scutter in a very large community study in Australia reported a prevalence of $37 \%$ in children aged $4-6$ years ${ }^{8}$.

Peak age incidence is between 4 and 12 years. It shows the typical clinical characteristics; pain is usually non-articular, predominantly affecting the anterior thigh, shin, and calf but not joints and is almost always bilateral. Children often describe cramping or aching that occurs in late afternoon or evening, hence the term BNLP. Pain is short-lived and intensity can be mild to very severe. Child is almost always pain free by morning. Absence of objective signs of inflammation on examination and normal laboratory investigations are important clues to diagnosis. GP is episodic, with pain-free intervals from days to months, but in severe cases can occur daily. Pain often follows a day increased physical activities or emotional stress. There is no association with serious organic disease. The natural history is of resolution after 18-24 months but the course may be more protracted. However, frequent episodes may have a major impact on the child and his family's daily routine, including absences from school and work, day time fatigue, reduced physical activity, and frequent or chronic use of pain relief medications ${ }^{10}$.

\section{Materials and Methods}

This cross sectional study was carried out among 60 children of both sexes 3-12 years old reporting to Paediatric OPD from July to

1. Lt Col Hosne Ara Yousuf, MBBS. DCH, MCPS, FCPS, Associate Professor of Paediatrics, AFMC, Dhaka, (E-mail: yousufhosne@gmail.com) 2. Col Md Ershad UI Quadir, MBBS, FCPS, Classified Specialist in Surgery, CMH, Dhaka. 
December 2012, with the complaints of unexplained limb pain. Patient presenting with recurrent and persistent (> 3 months) lower extremity pain were included in the study. The exclusion criteria consisted any abnormal systemic or local symptoms and signs. Laboratory tests, including complete blood count, erythrocyte sedimentation rate, serum calcium, serum inorganic phosphate and Vitamin D25 levels were performed in all children. GP was defined using Standard criteria8. With fulfillment of inclusion and exclusion criteria the prevalence of risk factors and the measures for their management were studied in the children. A structured questionnaire was designed and was filled up by the researcher herself to collect information about personal and family characteristics, recording physical examination and anthropometric measurement. The treatment regimens consisted of stretching exercise, massage and analgesic.

\section{Results}

Out of 60 patients of unexplained limb pain, 45(75\%) were diagnosed as GP and 15(25\%) patients non-GP; among them 6(10\%) were transient synovitis of hip, 1(1.7\%) was Legg Calve Perthes disease, $4(6.7 \%)$ were flat foot, fibromyalgia and Osgood Schlatter disease each was 2(3.3) in number (Table-I). Among the 45 GP patients, 26(57.7\%) were female and 19(42.3\%) were male but among 15 non-GP patients, 8(53.3\%) were female and $7(46.7 \%)$ were male. GP patients' mean age, weight and height was 7.4 years, $21.0 \mathrm{~kg}$ and $116.5 \mathrm{~cm}$ respectively. In contrary non-GP patients' mean age, weight and height was 8.9 years, 24.7 $\mathrm{kg}$ and $121.9 \mathrm{~cm}$ respectively (Table-II).

Table-III showed the prevalence of risk factors among study population. In GP $64.4 \%$ cases pain occur at night and $35.6 \%$ cases at evening. Patients having GP mostly complain of pain in calf (62.2\%) with next frequency in shin (35.6\%). Pain was least in hip and foot both having the frequency of $4.4 \%$. The frequency of pain was observed to be mostly at weekly interval (46.7\%) and daily occurrence was observed to be the least (8.9\%). Among study population $13.3 \%$ cases were overweight and $15.6 \%$ found to be obese. Prevalence of overweight, obesity, over activity and family history were specifically observed and recorded. These parameters were significantly high among cases. Overweight 6 (13.3\%) and obesity 7 (15.6\%), the number of cases were almost equal. Without therapy 3 cases of GP resolved, only rest and reassurance was adequate. Stretching exercise and analgesic has almost similar effect $26.7 \%$ and $31.1 \%$ respectively. $84.4 \%$ children responded well to massaging. Among GP 37(80.4\%) cases and non-GP(57.1\%) cases occur at slow growing period and only $9(19.6 \%)$ cases of GP and 6 (42.9\%) cases of non-GP occur at rapid growing period. So GP is more common in slow growing period than the non GP. In this study it can be said that GP is misnomer as it has no relation with rapid growth (Table-IV).
Table-l: Diagnosis of Unexplained Limb Pain $(n=60)$

\begin{tabular}{|l|l|c|c|}
\hline \multicolumn{2}{|c|}{ Type of pain } & Frequency & Percentage \\
\hline Growing pain & 45 & 75 \\
\hline \multirow{4}{*}{$\begin{array}{l}\text { Non-growing } \\
\text { pain }\end{array}$} & Transient Synovitis of hip & 6 & 10 \\
\cline { 2 - 4 } & Fibromyalgia & 2 & 3.3 \\
\cline { 2 - 4 } & Flat foot & 4 & 6.6 \\
\cline { 2 - 4 } & Legg Calve Perthes disease & 1 & 1.7 \\
\cline { 2 - 4 } & Osgood Schlatter disease & 2 & 3.3 \\
\cline { 2 - 4 } & Total & 15 & 25 \\
\hline
\end{tabular}

Table-II: Demographics of the GP ( $n=45)$ and non-GP $(n=15)$ population

\begin{tabular}{|l|l|c|c|}
\hline \multicolumn{2}{|c|}{ Characteristics } & $\begin{array}{c}\text { With GP } \\
\mathbf{n}(\%)\end{array}$ & $\begin{array}{c}\text { Without GP } \\
\mathbf{n}(\%)\end{array}$ \\
\hline \multirow{4}{*}{ Age in years } & $3-5$ & $16(35.5)$ & $2(13.3)$ \\
\cline { 2 - 4 } & $6-9$ & $18(40.0)$ & $4(26.7)$ \\
\cline { 2 - 4 } & $10-12$ & $11(24.4)$ & $9(60.0)$ \\
\cline { 2 - 4 } & Mean & 7.4 & 8.93 \\
\cline { 2 - 4 } & Range & $3-10$ & $5-12$ \\
\hline Weight in kg & Mean & 21.0 & 24.7 \\
\hline Height in cm & Mean & 116.5 & 121.9 \\
\hline Sex & Male & $19(42.2)$ & $7(46.7)$ \\
\cline { 2 - 4 } & Female & $26(57.8)$ & $8(53.3)$ \\
\hline
\end{tabular}

Table-III: Clinical profile of children presenting with growing pain $(n=45)$

\begin{tabular}{|c|c|c|}
\hline Characteristic & Frequency & Percentage \\
\hline \multicolumn{3}{|l|}{ Timing of pain } \\
\hline Evening & 16 & 35.6 \\
\hline Night & 29 & 64.4 \\
\hline \multicolumn{3}{|l|}{ Location of pain } \\
\hline Hip & 2 & 4.4 \\
\hline Thigh & 5 & 11.1 \\
\hline Popliteal & 12 & 26.7 \\
\hline Shin & 16 & 35.6 \\
\hline Calf & 28 & 62.2 \\
\hline Foot & 2 & 4.4 \\
\hline \multicolumn{3}{|l|}{ Frequency of pain } \\
\hline Daily & 4 & 8.9 \\
\hline Weekly & 21 & 46.7 \\
\hline Monthly & 14 & 31.1 \\
\hline 3 monthly & 6 & 28.9 \\
\hline \multicolumn{3}{|l|}{ Relationship with different factors } \\
\hline Overweight (85th-<95th centile) & 6 & 13.3 \\
\hline Obesity (BMI $\geq 95$ th centile) & 7 & 15.6 \\
\hline Overactivity & 21 & 46.7 \\
\hline Family history & 24 & 53.3 \\
\hline \multicolumn{3}{|l|}{ Therapeutic modalities adopted } \\
\hline No therapy, rest & 3 & 6.7 \\
\hline Stretching exercise & 12 & 26.7 \\
\hline Massaging & 38 & 84.4 \\
\hline Warm compression & 10 & 22.2 \\
\hline Anti-inflammatory-analgesic & 14 & 31.1 \\
\hline Others (ice or bandage applied) & 2 & 4.4 \\
\hline
\end{tabular}

Table-IV: Relation of Growing pain with Growing Period of Children $(n=60)$

\begin{tabular}{|l|c|c|c|}
\hline \multirow{2}{*}{ Pain Count } & \multicolumn{2}{|c|}{ Age Group } & \multirow{2}{*}{ Total } \\
\cline { 2 - 3 } & $\begin{array}{c}\text { Slow growing } \\
\text { period }\end{array}$ & $\begin{array}{c}\text { Rapid growing } \\
\text { period }\end{array}$ & \\
\hline Growing Pain & $37(80.4 \%)$ & $9(19.6 \%)$ & $46(75.4 \%)$ \\
\hline Non-Growing Pain & $8(57.1 \%)$ & $6(42.9 \%)$ & $14(24.6 \%)$ \\
\hline
\end{tabular}




\section{Discussion}

The prevalence of growing pains varies between studies. These may arise from different sample sizes, age ranges and lack of objective diagnostic criteria adopted. Kaspiris and Zafiropoulou shows a prevalence of $24.5 \%$ among 532 children aged 4-12 years ${ }^{11}$. We found the frequency of growing pain to be $75 \%$ in present study. Similar results (87\%) are found in Brazilian Children $^{12}$. Gender specific prevalence varies between studies. Pavone et a ${ }^{13}$ shows male are affected more than female and Angelos Kaspiris ${ }^{11}$ showed male to female ratio is 9:11. This study supports that GP is with female preponderance, the answer remains unclear.

Growing pain mainly affects children between the ages of $4-12$ years with peak incidence between the age 8 and 12 years $5.40 \%$ cases of GP in this study were found to be in 6-8 years age group. According to a study from the Lancet in 1928, the prevalence of growing pains was decreased in older age. Williams $M$ found $44.4 \%$ of 8 - to 10 -year-olds, $39.8 \%$ of 10 - to 12 -year-olds, and $21.2 \%$ of children older than 12 years had growing pains during routine examination ${ }^{14}$. Two-third (62.2\%) of children in current study had pain in calf muscle similar to $2 / 3$ rd found in Uziel study ${ }^{15}$. Pain occurred mostly at night with the greatest frequency being weekly, as was found in study of Pavone V. et a ${ }^{13}$ where $56.6 \%$ cases had pain during night with weekly frequency being $45 \%$ whereas night pain was $66.9 \%$ with weekly frequency of $28.1 \%$ was observed in study by Angelos ${ }^{11}$. This is consistent with present study.

Despite the increased frequency of GP, only one in five parents visited a doctor for this reason, irrespectively of the children's clinical manifestation ${ }^{11}$. Study by Kaspiris and Zafiropoulou did not exhibit significant difference between study group and general population, with the exception of white blood cells counts (WBC) and mean corpuscular volume (MCV) ${ }^{11}$. In our study no significant difference was observed among patients with GP. Considering the fact, we arrive to a conclusion that lab and radiological tests are of lesser importance and sometimes unnecessary. Proper assessment using Petersen's criteria and thorough physical examination will enable reaching a correct diagnosis. Hashkes et al. showed that $52 \%$ pain in GP was alleviated using analgesics ${ }^{16}$, whereas in others rest (10\%), analgesics (17.5\%) and $77.5 \%$ pain relief was achieved by massaging in Angelos Kaspiris study ${ }^{11}$. Kaspiris \& Zafiropoulou (2009) showed massaging (77.5\%) to be the most popular treatment ${ }^{11}$. In our research in addition to massaging (84.4\%) stretching exercise (26.7\%), warm compression (22.2\%) and use of analgesics (31.1\%) also constitute an effective way of management.

Since its first description in 1823, and later, in Bennie's work in 1984, when the term "Growing Pains" was coined, the pathogenesis of GP has remained unclear ${ }^{17}$. It may be due to low pain threshold, decrease bone strength, blood perfusion changes, anatomical/mechanical factors, unhappy family environment, familial predisposition and growth ${ }^{8}$. While many of these theories have not been supported or have been refuted, the lower pain threshold in children with GP along with the familial nature of disorder suggests that GP might be classified as a functional pain syndrome ${ }^{18}$. This report also suggests that GP is not related with growth. Evans et al stated $35.9 \%$ of parents linked growing pain with sudden attainment in height ${ }^{19}$, while Angelos Kaspiris showed corresponding percentage to be $14.6 \%$. The mean age of GP in our study is 7.4 years which is the slow growing period of the children; so GP is the misnomer as it does not occur in rapid growing period.

\section{Conclusion}

Growing pain is a frequent presenting complaint in paediatric rheumatology clinic. It is generally considered benign and time- limited condition. Clinical diagnosis is easy if precise inclusion and exclusion criteria in the history and physical examinations are meticulously followed. Treatment should be focused on family reassurance and education. Paeditrician must give due consideration in exclusion of other chronic musculoskeletal pain that commonly present as benign unexplained limb pain in childhood.

\section{References}

1. Al-Khattat A, Campell J. Recurrent limb pain in childhood ("Growing pains"). The Foot 2000; 10:117-23.

2. Duchamp M. Maladies de la croissance. In: Levrault FG, editor. Mémoires de medicine practique. Paris: Jean-Frédéric Lobstein; 1823.

3. Petersen H. Leg aches. Pediatr Clin North Am. 1977; 24(4):731-6.

4. Petersen H. Growing pains. Pediatr Clin North Am. 1986; 33(6):1365-72.

5. Abu-Arafeh I, Russel G. Recurrent limb pain in school children. Arch Dis Child. 1996; 74(4):336-9.

6. De Inocencio J. Epidemiology of musculoskeletal pain in primary care. Arch Dis Child. 2004; 89(5):431-4.

7. www.betterhealthvic. Gov.au: Growing pain. Better Health Channe.I 2010:1-2.

8. Evans AM, Scutter SD. Prevalence of "growing pains" in young children. J Pediatr. 2004; 145(2):255-8.

9. Oster J, Nielson A. Growing pain: A clinical investigation of a school population. Acta Paediatr Scand 1972; 61(3):329-34.

10. Uziel Y, Hashkes PJ. Growing Pains in Children. Pediatr Rheumatol Online. J 2007; 5:5.

11. Kaspiris A, Zafiropoulou C. Growing pains in children: Epidemiological analysis in a Mediterranean population. Joint Bone Spine. 2009; 76(5):486-90.

12. Almeida de Piano LP, Golmia RP, Golmia APF et al. Diagnosis of growing pain in a Brazilian pediatric population: A prospective 
investigation. Einstein (Sao Paulo). 2010; 8(4):430-2.

13. Pavone V, Lionett $E$, Gargano V et al. Growing pains: A study of 30 cases and a review of the literature. J Paediatric Orthop. 2011; 31(5):606-9.

14. Williams MF. Rheumatic conditions in school-children. Lancet. 1928; 211:720-1.

15. Uziel $Y$, Chapnick $G$, Jaber $L$ et al. Five years outcome of children with growing pains: Correlation with pain threshold. J Pediatr. 2010; 156(5):838-40.
16. Haskesh PJ, Friedland $\mathrm{O}$, Jaber $\mathrm{L}$ et al. Decreased pain thresh old in children with growing pains. J Rheumatol. 2004; 31(3):610-3. 17. Bennie PB. Growing Pains. Arch Pediatr .1894; 11:337-47. 18. Mayer EA, Bushnel MC. Functional pain syndrome: Presentation and Pathophysiology, Seattle: IASP Press 2009:431-565.

19. Evans AM, Scutter SD, Lang LG et al. "Growing pains" in young children: a study of the profile, experiences and quality of life issues of four- to six-year-old children with recurrent leg pain. The Foot. 2006; 16:120-4. 